\title{
Uptake and willingness to use PrEP among Chinese gay, bisexual and other men who have sex with men with experience of sexualized drug use in the past year
}

Zixin Wang ${ }^{1,2^{*}}$, Phoenix K. H. Mo ${ }^{1}$, Mary Ip ${ }^{1}$, Yuan Fang ${ }^{3}$ and Joseph T. F. Lau ${ }^{1,2}$

\begin{abstract}
Background: Sexualized drug use (SDU) refers to use of any psychoactive substance before/during sexual intercourse. Chemsex is a subset of SDU, which is defined as the use of some specific psychoactive substances (methamphetamine, mephedrone, $\gamma$-hydroxybutyrate, ketamine and cocaine) before/during sexual intercourse. SDU and chemsex are prevalent among gay, bisexual and other men who have sex with men (GBMSM). This study investigated uptake and willingness to use pre-exposure prophylaxis (PrEP) among a sample of GBMSM in Hong Kong with experience of SDU in the past year.
\end{abstract}

Methods: A total of 600 GBMSM were recruited by convenient sampling through outreaching in gay venues, online recruitment and peer referral. Participants completed a cross-sectional anonymous telephone interview. This study was based on a subsample of 580 GBMSM self-reported as HIV negative/unknown sero-status.

Results: Of the participants, $82(14.1 \%)$ and $37(6.4 \%)$ had experience of SDU and chemsex in the past year. The prevalence of PrEP uptake was $4.0 \%$ among all participants and $14.6 \%$ among those with experience of SDU in the past year. Among GBMSM with experience of SDU in the past year who were not on PrEP $(n=70), 67.1 \%$ were willing to use daily oral PrEP in the next 6 months. Multivariate logistic regression models showed that positive attitudes toward PrEP (AOR: 2.37, 95\%Cl: 1.47, 3.82), perceived support from significant others to use PrEP (AOR: 9.67, 95\%Cl: 2.95, 31.71), and perceived behavioral control of using PrEP (AOR: 19.68, 95\%Cl: 5.44, 71.26) were significantly associated with higher willingness to use PrEP.

Conclusion: GBMSM with experience of recent SDU are potentially good candidates of PrEP implementation. This group of GBMSM reported high prevalence of uptake and willingness to use PrEP. Perceptions related to PrEP based on the Theory of Planned Behavior were significantly associated with willingness to use PrEP.

Keywords: Pre-exposure prophylaxis, Willingness to use, Gay, bisexual and other men who have sex with men, Sexualized drug use, China

\footnotetext{
*Correspondence: wangzx@cuhk.edu.hk

${ }^{1}$ Centre for Health Behaviours Research, JC School of Public Health and

Primary Care, Faculty of Medicine, The Chinese University of Hong Kong, Hong Kong SAR, China

${ }^{2}$ Shenzhen Research Institute, The Chinese University of Hong Kong, Shenzhen, China

Full list of author information is available at the end of the article
}

(c) The Author(s). 2020 Open Access This article is licensed under a Creative Commons Attribution 4.0 International License, which permits use, sharing, adaptation, distribution and reproduction in any medium or format, as long as you give appropriate credit to the original author(s) and the source, provide a link to the Creative Commons licence, and indicate if changes were made. The images or other third party material in this article are included in the article's Creative Commons licence, unless indicated otherwise in a credit line to the material. If material is not included in the article's Creative Commons licence and your intended use is not permitted by statutory regulation or exceeds the permitted use, you will need to obtain permission directly from the copyright holder. To view a copy of this licence, visit http://creativecommons.org/licenses/by/4.0/. The Creative Commons Public Domain Dedication waiver (http://creativecommons.org/publicdomain/zero/1.0/) applies to the data made available in this article, unless otherwise stated in a credit line to the data. 


\section{Background}

The HIV epidemic is severe among gay, bisexual and other men who have sex with men (GBMSM) in China, as the overall HIV prevalence and incidence in this group are both high and increasing $(9.9 \%$ and 5.6 per 100 person-year in 2016) [1, 2]. In Hong Kong, China, where the study was conducted, the HIV prevalence and incidence among GBMSM was $6.54 \%$ and 1.0 per 100 person-year in 2017, respectively [3,4]. Out of the 681 new HIV cases in 2017, 63\% acquired it via homosexual or bisexual contact [3].

In line with numerous published studies, psychoactive substances were defined as the following: 1) ketamine, 2) methamphetamine, 3) cocaine, 4) cannabis, 5) ecstasy, 6) Dormicum/Halcion/Erimin 5/non-prescription hypnotic drugs, 7) heroin, 8) cough suppressant (not for curing cough), 9) amyl nitrite (popper), 10) GHB/GBL ( $\gamma$-hydroxybutyrate), 11) 5-methoxy-N, N-diisopropyltryptamine (Foxy), and 12) mephedrone [5-7]. Sexualized drug use (SDU) refers to the use of any of the abovementioned psychoactive substances before/during sexual intercourse [8]. Chemsex is considered as a subset of SDU, which is commonly defined as the use of some specific psychoactive substances (methamphetamine, mephedrone, $\gamma$-hydroxybutyrate $(\mathrm{GHB} / \mathrm{GBL})$, ketamine and cocaine) before/during sexual intercourse [57]. These psychoactive substances were mainly used to facilitate, initiate, prolong, sustain and intensify sexual encounter $[8,9]$.

A high prevalence of SDU was reported among GBMSM in the United States (43\%), Australia (54\%), and Western Europe (18-54\%) [5, 6, 10-13]. The rates were slightly lower in Asia, ranged from $28 \%$ in mainland China, $18 \%$ in Thailand, $14 \%$ in Vietnam, to $7 \%$ in Malaysia [14]. Worldwide, the prevalence of chemsex ranged from 3 to $35 \%$ among GBMSM [7, 13, 15]. A recent study reported that $12 \%$ of GBMSM in Hong Kong had SDU in the past 6 months (excluding the use of amyl nitrite alone) [16]. Psychoactive substances adversely affect users' capacity to perceive and respond to risks during sexual encounters, leading to high-risk sexual practices (e.g., condomless anal intercourse (CAI), group sex, fisting, etc.) [17] and hence HIV and other sexually transmitted infections (STI) [7]. However, there was a lack of effective behavioral interventions in reducing psychoactive substance use and sexual risk behaviors among GBMSM with experience of SDU/chemsex [18-21].

Pre-exposure prophylaxis (PrEP) is a potentially risk reduction measure for GBMSM with experience of SDU/chemsex, which refers to the initiation of Tenofovir Disoproxil Fumarate/Emtricitabine before and during periods of HIV exposure among HIV-negative individuals in order to prevent HIV acquisition [22]. With good adherence, PrEP could significantly reduce the risk of
HIV infection among various at-risk groups, including GBMSM [22] and drug users [23]. The World Health Organization (WHO) strongly recommends PrEP to all population at substantial risk of HIV infection [24]. Clinical trials did not identify any significant safety concerns with daily PrEP use among psychoactive substance users [23].

A systematic review suggested that prevalence of PrEP use among GBMSM varied from 2.5\% in Australia, 2$5 \%$ in Western Europe, to $9-12 \%$ in the United States [25]. PrEP use is less common among GBMSM in Hong Kong (3.6\% in 2017) [3]. Willingness to use PrEP among GBMSM also varied between 19.1 and $96.2 \%$, with a pooled estimate of $57.8 \%$ [26]. Meta-analyses suggested that accessibility of PrEP and social stigma contributed to willingness to use PrEP among GBMSM, and country-specific factors were likely to affect willingness [26]. In Hong Kong, due to the high cost of obtaining formal prescription in private clinics (US\$1000/month) and limited coverage of the PrEP demonstration project (70 participants), majority of local GBMSM PrEP users obtained the medication from overseas clinics or through online purchase [3]. Previous studies showed that about half of Hong Kong GBMSM in general were willing to use free PrEP [3, 27]. GBMSM with experience of SDU might have higher interest to use PrEP. One study in Hong Kong found that GBMSM with recent or ongoing SDU showed higher awareness of PrEP [28]. While another study in the United States reported that GBMSM using amyl nitrite had higher prevalence of PrEP use [29].

In order to develop effective intervention to promote PrEP, it is important to understand factors associated with willingness to use PrEP among GBMSM with experience of SDU. At least three quantitative studies investigated factors associated with willingness to use PrEP among high-risk drug users [30-32]. These studies had found a number of factors to be associated with willingness to use PrEP, including age, types and frequency of drug use, perceptions of HIV risk and PrEP (e.g., perceived effectiveness, would be less worried if on PrEP, concerns related to side effects, and confident to use/adhere to PrEP) [30-32]. However, these studies mainly targeted heterosexuals and injective drug users. The findings may not be generalized to GBMSM with experience of SDU. Only one qualitative [33] investigated reasons for PrEP use among substance-using GBMSM. The results suggested that being able to relax and not having to worry about getting HIV, and increased comfort and openness to have sexual relationship with HIV positive partners were facilitators of PrEP use among substance-using GBMSM. The participants of the qualitative study also expressed concerns that substance use/SDU would disrupt their daily routine and 
negatively affect their ability to take PrEP or adhere to daily PrEP [33]. These factors were considered by this study.

Theory-based interventions are more effective than non-theory-based ones [34]. In this study, we applied the Theory of Planned Behavior (TPB) [35] as the theoretical framework. The TPB postulates that behavioral intention to adopt a health-related behavior (e.g., use PrEP) is a strong predictor of actual behavior. In order to form such an intention, one would evaluate the pros and cons of the behavior (positive and negative attitudes), consider whether their significant others would support such behavior (perceived subjective norm), and appraise how much control one has over the behavior (perceived behavioral control). In recent published studies, the TPB has been successfully used to explain willingness to use PrEP among GBMSM in general [27], transgender women sex workers [36] and heterosexual population [37]. Moreover, many published studies also used the TPB to explain sexual behaviors [38-40], and utilization of HIV testing [41] and antiretroviral therapy [42].

In addition, mental health may be particular salient for PrEP use. Prevalence of mental health problems (e.g., depression, anxiety, and stress) are much higher among GBMSM than that of heterosexual men [43, 44]. Although acceptance of same-sex relationships is growing in many western countries, stigma toward homosexuals is still widespread in China [45]. As a result, previous studies reported high prevalence of mental health problems among GBMSM in China [46, 47]. Moreover, psychoactive substance use and SDU were associated with poorer mental health status among GBMSM [48-51]. Poor mental health status was found to be a barrier to start and adhere to PrEP [36, 52, 53]. For instance, anxiety symptoms were associated with lower willingness to use PrEP among transgender women sex workers in China [36]. Therefore, in this study, we investigated the associations between depressive/anxiety symptoms and willingness to use PrEP among GBMSM with experience of SDU in the past year.

To the best of our knowledge, there have been no study investigating willingness to use PrEP and associated factors among GBMSM with experience of SDU. Their prevalence of uptake and willingness to use PrEP as well as associated factors may be different from GBMSM without experience of SDU. To address these gaps, this study investigated PrEP uptake and willingness to use daily PrEP among GBMSM in Hong Kong with experience of SDU in the past year. Potentially associated factors were also investigated, including variables related to socio-demographics, service utilization, sexual behaviors, patterns of SDU, perceptions related to PrEP based on the TPB, and mental health status.

\section{Methods}

\section{Participants and data collection}

Data used in this study were derived from a cross-sectional study among GBMSM in Hong Kong from April to December, 2018. Participants were: 1) Hong Kong Chinese speaking men, 2) aged 18 years or above, and 3) had anal intercourse with at least one man in the last 12 months. Participants were recruited through multiple sources. Initially, a recent mapping exercise was conducted by the government and identified 12 gay bars and 16 gay saunas in Hong Kong. On approval of the owners, trained and experienced fieldworkers approached visitors in these venues at different time slots during weekdays and weekends. They briefed the prospective participants on details of the study and gave them an information sheet on site. Those who showed interest to join the study were asked some questions to screen their eligibility. Online outreaching to potential GBMSM was also used for study recruitment. The research team posted the information of this study periodically as new discussion topics on two popular gay websites in Hong Kong which are commonly used by GBMMS to seek sex partners. If prospective participants were interested in this study, they could contact the interviewers through private messaging or other means (e.g., WhatsApp, telephone, email, etc.). Recruitment was supplemented by peer referrals. Fieldworkers screened participants' eligibility, guaranteed anonymity, right to quit at any time and that refusal would not affect chance to use any services. As approved by the ethics committee, verbal instead of written informed consent was obtained in order to maintain anonymity, and fieldworkers signed a form pledging that the participants had been fully informed about the study. Participants provided multiple contacts (mobile, emails, social media account, etc.) to fieldworkers and then made appointment to conduct a telephone interview.

During the interviews, trained interviewers confirmed participants' eligibility over phone, and participants again provided consent to participate in the study. Interviewers then conducted telephone interview with the participants which took about $30 \mathrm{~min}$ to complete. At least five followup calls were made in different time slots during weekdays and weekends before considering the case as a non-contact. Incentive was provided to participants upon completion to compensate their time spent. A HK\$50 supermarket or café coupon was mailed to an address provided by the participant, in an envelope containing no names, nor any information, about the study. Telephone numbers/addresses were cross-checked to avoid repetition. Ethics approval was obtained from the Survey and Behavioral Research Ethics Committee of the Chinese University of Hong Kong.

\section{Measures}

\section{Design of the questionnaire}

A panel consisted of a public health researcher, an epidemiologist, one psychologist, one GBMSM and one 
non-governmental organization (NGO) worker formed to develop the questionnaire. Based on literature review and informal consultation involving all panel members, a tentative list of potential measurement was drafted. The panel members then rated the relevancy and importance on a pool of items in the list. A questionnaire was drafted and pilot among five GBMSM selected by purposive sampling. The five GBMSM commented on the relevancy, wording and content of the draft questionnaire. Based on comments made by GBMSM and all panel members, revision was made accordingly. The semi-final questionnaire was then pilot among another five GBMSM to seek further comments on wording and relevancy. All panel members then finalized the questionnaire. Participants of the pilot study did not take part in the actual survey.

Socio-demographics, utilization of HIV prevention services, sexual behaviors and mental health status

Participants were asked to report on sociodemographics, sexual orientation, HIV prevention services utilization, and history of STIs other than HIV. Queried sexual behaviors included anal intercourse with regular and non-regular male sex partners, CAI with men, and multiple male sex partnerships in the last year. Regular male sex partners (RP) were defined as lovers/ stable boyfriends, while non-regular male sex partners (NRP) were defined as casual sex partners and/or male sex workers. Measurements of these variables had been used some published studies targeting GBMSM in Hong Kong [27, 54].

Probable depression was measured by validated Chinese version of the Center for Epidemiologic Studies Short Depression Scale (CES-D-10) [55], which has been widely used in studies targeting GBMSM $[56,57]$. Scores $\geq 10$ indicated presence of clinically significant depressive symptoms (range: 0-30) [55]. Anxiety symptoms were measured by validated Chinese version of the 7-item Generalized Anxiety Disorder Scale (GAD-7) [58]. A cut-off score of 15 is recommended to define severe anxiety [58]. In this study, the Cronbach alpha of the CESD-10 and the GAD-7 was 0.893 and 0.930 , respectively.

\section{Patterns of SDU}

Participants with experience of SDU in the past year were asked to report on the details about SDU, including: 1) types of psychoactive substance used during SDU in the past year, 2) poly-use of psychoactive substances during SDU in the past year, 3) time since the first episode of SDU, 4) frequency of SDU in the past year, 5) CAI during SDU in the past year, and 6) utilization of drug cessation/rehabilitation services in lifetime. Queried details of their most recent episode of SDU included number of people involved, use of alcohol and erectile dysfunction drug, and presence of group sex and CAI.

\section{PrEP use and willingness to use PrEP}

Participants who were currently on PrEP were asked about sources of PrEP, methods of PrEP use (i.e., daily PrEP, on-demand PrEP, and holiday PrEP: using PrEP either daily or on-demand only in some period of time). Daily PrEP users were asked about whether they had missed more than three doses of PrEP within a week in the past month. Such measurement of adherence was commonly used in published studies [59].

Participants with experience of SDU in the past year who were not on PrEP were briefed with the following: "PrEP is a strategy that promotes taking oral antiretroviral drugs to prevent HIV infection among HIV-negative individuals. PrEP is strongly recommended by the WHO as an additional HIV prevention strategy for MSM. You are required to take PrEP once every day when you are using it in order to achieve its effect in preventing HIV infection. Daily use of oral PrEP could reduce risk of HIV infection by 92\%. PrEP has possible side effects such as nausea, vomiting and headache". They were then asked whether they were willing to take a once-daily oral pill as PrEP in the next 6 months (Response categories: $1=$ definitely not, 2 = probably not, 3 = neutral, 4 = probably will, 5 = definitely will). Responses were then dichotomized. Willingness to use daily PrEP was defined as "probably will" or "definitely will". Such a definition has been commonly used in previous studies [27, 60, 61]. For those with willingness to use PrEP, they were further asked about the maximum amount (in HK\$) they were willing to pay per month for using daily PrEP.

\section{Perceptions related to PrEP based on the TPB}

Two scales based on the TPB were constructed for this study, they are the 3-item Positive Attitude Scale and the 5-item Negative Positive Scale (response categories: 1 = disagree, 2 = neutral, 3 =agree). The Cronbach's alpha for the Positive Attitude Scale and the Negative Attitude Scale was 0.648 and 0.747, single factors were identified by explanatory factor analysis, explaining for $56.6-61.6 \%$ of the total variances. We extracted one item from the validated Subjective Norm Scale (i.e., 'people who are important to you will support you to use PrEP'; response categories: 1 = disagree, 2 =neutral, 3 =agree) [27] to measure perceived subjective norm related to PrEP. In addition, one item was extracted from the validated Perceived Behavioral Control Scale with some modification to measure perceived behavioral control related to PrEP use (i.e., 'In general, you are confident in taking PrEP every day in the next six months'; response categories: 1 = disagree, 2 = neutral, 3 = agree) [27]. 


\section{Statistical analysis}

Using SDU in past year (among all participants) and willingness to use PrEP (among participants with experience of SDU in the past year who were not on PrEP) as the dependent variables, crude odds ratios $(\mathrm{ORu})$ of independent variables of interest were obtained by logistic regression models. Two summary multivariate logistic regression models were fit for these two dependent variables, using independent variables with $p<0.05$ in univariate analysis as candidates. Adjusted odds ratios (AOR) and respective 95\% confidence interval (CI) were obtained from the analyses. SPSS version 21.0 was used for data analysis, with $p$ values $<0.05$ taken as statistically significant.

\section{Results}

Socio-demographics, HIV prevention service utilization, sexual behaviors and mental health status

Out of 1131 prospective participants being approached through outreach in gay venues $(n=211)$, online recruitment $(n=607)$ and peer referral $(n=313), 906$ showed interest to join the study and left their contact information. All these 906 participants were successfully contacted, 711 were screened to be eligible. Of eligible participants, 600 provided verbal informed consent and completed the telephone interview. The main reason for not providing informed consent was lack of time to complete the survey $(n=71)$, while the other 40 refusals did not specify their reason. This study was based on 580 GBMSM self-reported to be HIV negative/unknown HIV sero-status.

Most participants were aged $18-30$ years (56.6\%), currently single $(84.0 \%)$, full-time employed $(84.5 \%)$, with monthly personal income of at least $\mathrm{HK} \$ 20,000 /$ month (57.5\%), and had attained at least a college education (84.5\%). Over half had tested for HIV (71.6\%) and had used other forms of HIV prevention services (55.3\%) in the past year. In addition, $19.5 \%$ self-reported a history of STI other than HIV. In the last year, 85.3 and $60.9 \%$ had anal intercourse with regular and non-regular male sex partners, respectively. A total of 39.5 and $69.3 \%$ participants reported CAI with men and multiple male sex partnerships, respectively. The prevalence of probable depression and probable case of severe anxiety was 35.9 and $6 \%$, respectively. (Table 1 ).

Prevalence of SDU in the past year and associated factors Among participants, $82(14.1 \%)$ and 37 (6.4\%) reported SDU and chemsex in the past year, respectively.

During SDU in the past year, popper (80.5\%), Methamphetamine (31.7\%), and GHB/GBL (31.7\%) were the most commonly used psychoactive substances; $30.5 \%$ reported poly-use of psychoactive substances, and 39.3\% reported CAI. Only 1.9 and $7.5 \%$ had ever utilized drug cessation/rehabilitation provided by governmental and non-governmental organizations. In the most recent episode of SDU, 21.7\% involved more than two people, 14.5 and $30.1 \%$ used alcohol and erectile dysfunction drugs, 19.3 and $50.6 \%$ had group sex and CAI. (Table 2).

In multivariate logistic regression model, participants who had utilized other forms of HIV prevention services (AOR: 1.77, 95\%CI: 1.03, 3.05), had anal intercourse with NRP (AOR: 7.75, 95\%CI: 2.30, 26.09), and CAI with men (AOR: 2.46, 1.44, 4.21) reported higher prevalence of SDU in the past year. As compared to participants without experience of SDU in the past year, those with such experience were more likely to use PrEP (AOR: 4.09, $95 \%$ CI: 1.56, 10.73). Higher education level was associated with lower prevalence of SDU in the past year (AOR: 0.36, 95\%CI: 0.19, 0.69). (Table 1).

\section{PrEP uptake and willingness to use daily oral PrEP}

Twenty-three participants (4.0\%) were on PrEP at the date of the survey. Sources of their PrEP included online purchase $(7 / 23,30.4 \%)$, clinics in Thailand $(6 / 23,26.1 \%)$, clinics in Hong Kong (3/23, 13.0\%), the ongoing PrEP demonstration project in Hong Kong $(6 / 23,26.1 \%)$, and friends $(1 / 23,4.4 \%)$. Majority of them $(14 / 23,60.9 \%)$ were taking daily PrEP, six (26.1\%) were using ondemand PrEP, and three (13.0\%) were on holiday PrEP. Five out of 14 daily PrEP users (35.7\%) reported suboptimal adherence to daily regimen in the past month.

Among 70 participants with experience of SDU in the past year who were not on PrEP, $67.1 \%$ were willing to use daily oral PrEP in the next 6 months. Among 28 participants who had chemsex in the past year who were not on PrEP, 19 (67.9\%) showed willingness to use daily oral PrEP in the next 6 months.

\section{Factors associated with willingness to use daily oral PrEP in the next six months among GBMSM with SDU in the past year}

Multivariate logistic regression model showed that three out of four constructs of the TPB were significantly and positively associated with willingness to use PrEP. They were: 1 ) the Positive Attitude Scale (AOR: 2.37, 95\%CI: $1.47,3.82), 2)$ perceived support from significant others to use PrEP (subjective norm) (AOR: 9.67, 95\%CI: 2.95, 31.71), and 3) perceived behavioral control of taking PrEP every day in the next 6 months (AOR: 19.68, 95\%CI: 5.44, 71.26). (Tables 3 \& 4).

\section{Discussion}

Our findings showed that $4 \%$ of our sampled GBMSM were on PrEP, rate that was comparable to that of a representative GBMSM survey conducted in 2017 (3.6\%) [3]. Our hypothesis that GBMSM with experience of recent SDU had higher interest to use PrEP was 
Table 1 Characteristics of GBMSM with and without experience of sexualized drug use (SDU) in the past year

\begin{tabular}{|c|c|c|c|c|c|}
\hline & \multirow{2}{*}{$\begin{array}{l}\text { All } \\
(n=580) \\
\%\end{array}$} & \multirow{2}{*}{$\begin{array}{l}\text { Without experience of SDU } \\
\text { in the past year } \\
(n=498) \\
\%\end{array}$} & \multirow{2}{*}{$\begin{array}{l}\text { With experience of SDU in the } \\
\text { past year }(n=82) \\
\%\end{array}$} & \multicolumn{2}{|c|}{$\begin{array}{l}\text { With vs. without experience } \\
\text { of SDU in the past year }\end{array}$} \\
\hline & & & & OR $(95 \% \mathrm{Cl})$ & AOR $(95 \% \mathrm{Cl})$ \\
\hline \multicolumn{6}{|l|}{ Socio-demographic characteristics } \\
\hline \multicolumn{6}{|l|}{ Age group } \\
\hline $18-30$ & 56.6 & 57.6 & 50.0 & 1.0 & \\
\hline $31-40$ & 31.6 & 30.5 & 37.8 & $\begin{array}{l}1.43(0.86 \\
2.37)\end{array}$ & \\
\hline$>40$ & 11.9 & 11.8 & 12.2 & $\begin{array}{l}1.19(0.56 \\
2.50)\end{array}$ & - \\
\hline \multicolumn{6}{|l|}{ Highest educational level attained } \\
\hline Senior high or below & 15.5 & 14.3 & 23.2 & 1.0 & 1.0 \\
\hline College or above & 84.5 & 85.7 & 76.8 & $\begin{array}{l}0.55(0.31 \\
0.98)^{*}\end{array}$ & $\begin{array}{l}0.36(0.19 \\
0.69)^{* *}\end{array}$ \\
\hline \multicolumn{6}{|l|}{ Current marital status } \\
\hline Currently single & 84.0 & 84.9 & 78.0 & 1.0 & \\
\hline Married/cohabited with a man & 15.7 & 14.7 & 19.8 & $\begin{array}{l}1.63(0.91 \\
2.91) \dagger\end{array}$ & \\
\hline Married/cohabited with a woman & 0.3 & 0.4 & 0.0 & N.A. & - \\
\hline \multicolumn{6}{|l|}{ Monthly personal income (HK\$) } \\
\hline$<10,000$ & 13.4 & 12.7 & 18.3 & 1.0 & \\
\hline $10,000-19,999$ & 29.1 & 28.1 & 35.4 & $\begin{array}{l}0.87(0.44 \\
1.74)\end{array}$ & \\
\hline $20,000-39,999$ & 36.7 & 37.8 & 30.5 & $\begin{array}{l}0.56(0.28 \\
1.13)\end{array}$ & \\
\hline 40,000 and above & 19.7 & 20.5 & 14.6 & $\begin{array}{l}0.49(0.22 \\
1.12) \dagger\end{array}$ & \\
\hline Refuse to disclose & 1.0 & 1.0 & 1.2 & $\begin{array}{l}0.84(0.09 \\
7.73)\end{array}$ & - \\
\hline \multicolumn{6}{|l|}{ Current employment status } \\
\hline Full-time & 83.6 & 85.1 & 74.4 & 1.0 & 1.0 \\
\hline $\begin{array}{l}\text { Part-time/unemployed/retired/ } \\
\text { students }\end{array}$ & 16.4 & 14.9 & 25.6 & $\begin{array}{l}1.97(1.13, \\
3.43)^{*}\end{array}$ & $\begin{array}{l}1.37(0.74 \\
2.56)\end{array}$ \\
\hline \multicolumn{6}{|l|}{ Sexual orientation } \\
\hline Homosexual & 90.7 & 90.4 & 92.7 & 1.0 & \\
\hline Bisexual & 8.4 & 8.6 & 7.3 & $\begin{array}{l}0.83(0.34 \\
2.01)\end{array}$ & \\
\hline Heterosexual & 0.9 & 1.0 & 0.0 & N.A. & - \\
\hline \multicolumn{6}{|l|}{ Channels of recruitment } \\
\hline Outreach in gay venues & 14.1 & 13.3 & 19.5 & 1.0 & \\
\hline Online recruitment & 57.6 & 58.6 & 51.2 & $\begin{array}{l}0.59(0.31 \\
1.12)\end{array}$ & \\
\hline Peer referral & 28.3 & 28.1 & 29.3 & $\begin{array}{l}0.71(0.35 \\
1.42)\end{array}$ & - \\
\hline
\end{tabular}

\section{Service utilization}

HIV testing in the last 12 months

No

Yes
$28.4 \quad 29.9$

$71.6 \quad 70.1$
19.5

80.5
1.0

$1.76(0.99$ 3.14)† 
Table 1 Characteristics of GBMSM with and without experience of sexualized drug use (SDU) in the past year (Continued)

\begin{tabular}{|c|c|c|c|c|c|}
\hline & \multirow{2}{*}{$\begin{array}{l}\text { All } \\
(n=580) \\
\%\end{array}$} & \multirow{2}{*}{$\begin{array}{l}\text { Without experience of SDU } \\
\text { in the past year } \\
(n=498) \\
\%\end{array}$} & \multirow{2}{*}{$\begin{array}{l}\text { With experience of SDU in the } \\
\text { past year }(n=82) \\
\%\end{array}$} & \multicolumn{2}{|c|}{$\begin{array}{l}\text { With vs. without experience } \\
\text { of SDU in the past year }\end{array}$} \\
\hline & & & & OR $(95 \% \mathrm{Cl})$ & AOR $(95 \% \mathrm{Cl}$ \\
\hline \multicolumn{6}{|c|}{ Other HIV prevention services in the last 12 months (e.g., condom distribution, peer education, pamphlet and lectures) } \\
\hline No & 44.7 & 46.8 & 31.7 & 1.0 & 1.0 \\
\hline Yes & 55.3 & 53.2 & 68.3 & $\begin{array}{l}1.89(1.15 \\
3.11)^{*}\end{array}$ & $\begin{array}{l}1.77(1.03, \\
3.05)^{*}\end{array}$ \\
\hline
\end{tabular}

\section{History of sexual transmitted infections}

History of sexually transmitted infections other than HIV

$\begin{array}{llllll}\text { No } & 80.5 & 82.9 & 65.9 & 1.0 & 1.0 \\ \text { Yes } & 19.5 & 17.1 & 34.1 & \mathbf{2 . 5 2 ( 1 . 5 1 ,} 1.72(0.97, \\ \mathbf{4 . 2 1})^{* * * *} & 3.07) \dagger\end{array}$

\section{Sexual behaviors in the last 12 months}

Had had anal intercourse with regular male sex partners (RP)

\begin{tabular}{|c|c|c|c|}
\hline No & 14.7 & 13.5 & 22.0 \\
\hline Yes & 85.3 & 86.5 & 78.0 \\
\hline
\end{tabular}

Had had anal intercourse with non-regular male sex partners (NRP)

$\begin{array}{llll}\text { No } & 39.1 & 44.0 & 9.8 \\ \text { Yes } & 60.9 & 56.0 & 90.2\end{array}$

Condomless anal intercourse (CAl) with men

$\begin{array}{llll}\text { No } & 60.5 & 63.7 & 41.5 \\ \text { Yes } & 39.5 & 36.3 & 58.5\end{array}$

Multiple male sex partnerships

\begin{tabular}{|c|c|c|c|}
\hline No & 30.7 & 34.1 & 9.8 \\
\hline Yes & 69.3 & 65.9 & 90.2 \\
\hline
\end{tabular}

$\mathbf{0 . 5 5}(\mathbf{0 . 3 1}, \quad 0.90(0.46$ 0.99** 1.73$)$

\section{se of pre-exposure prophylaxis (PrEP)}

Currently on PrEP

\begin{tabular}{|c|c|c|c|c|c|}
\hline No & 96.0 & 97.8 & 85.4 & 1.0 & 1.0 \\
\hline Yes & 4.0 & 2.2 & 14.6 & $\begin{array}{l}7.59(3.23 \\
17.86)^{* * * *}\end{array}$ & $\begin{array}{l}4.09(1.56 \\
10.73)^{* *}\end{array}$ \\
\hline
\end{tabular}

\section{Mental health status}

\begin{tabular}{|c|c|c|c|c|c|}
\hline \multicolumn{6}{|l|}{ Depressive symptoms } \\
\hline $\begin{array}{l}\text { No clinical depressive symptoms (CES- } \\
\text { D-10 score }<10 \text { ) }\end{array}$ & 64.1 & 65.7 & 54.9 & 1.0 & \\
\hline $\begin{array}{l}\text { Presence of clinical depressive } \\
\text { symptoms (CES-D-10 score } \geq 10 \text { ) }\end{array}$ & 35.9 & 34.3 & 45.1 & $\begin{array}{l}1.57(0.98 \\
2.52) \dagger\end{array}$ & - \\
\hline \multicolumn{6}{|l|}{ Anxiety } \\
\hline No/mild anxiety (GAD-7 score $<15)$ & 94.0 & 94.4 & 91.5 & 1.0 & \\
\hline Severe anxiety (GAD-7 score $\geq 15$ ) & 6.0 & 5.6 & 8.5 & $\begin{array}{l}1.57(0.66 \\
3.72)\end{array}$ & - \\
\hline
\end{tabular}

OR Crude odds ratios

AOR: multivariate odds ratios obtained by multivariate logistic regression using variables in Table 1 that were found to be statistically significant in the univariate analysis as candidates

95\% Cl 95\% confidence interval

$+0.05<P<0.10$ * $P<0.05, * * P<0.01$, *** $P<0.001$

N.A. Not applicable; --: not considered in the model 
Table 2 Patterns of SDU and perceptions related PrEP among GBMSM with experience of SDU in the past year

\begin{tabular}{ll}
\hline & $\% /$ Mean \\
& $(\mathrm{SD})$ \\
\hline Patterns of SDU & $(n=82)$
\end{tabular}

Types of psychoactive substance used during SDU in past year

Ketamine

Methamphetamine

Cocaine

Cannabis

Ecstasy

Dormicum / Halcion / Erimin 5 / Hypnotic drugs (nonprescription)

Heroin

Cough suppressant (not for curing cough)

Amyl nitrite

GHB/GBL

5-methoxy-N, N-diisopropyltryptamine (Foxy)

Mephedrone

Poly-use of psychoactive substances in lifetime

No

Yes

Time since the first episode of SDU

$<1$ year

$1-2$ years

$3-5$ years

$>5$ years

Frequency of SDU in the past year

1 episode/month

$1-2$ episodes/month

$\geq 3$ episodes/month

Condomless anal intercourse during SDU in the past year

No

Yes

51.2

Drug cessation/rehabilitation services provided by governmental organizations

No

Yes

Drug cessation/rehabilitation services provided by non-governmental organizations

No

Yes

Details of the most recent episode of SDU

Number of participants

2

$\geq 3$

Alcohol consumption

No
Table 2 Patterns of SDU and perceptions related PrEP among GBMSM with experience of SDU in the past year (Continued)

\begin{tabular}{ll}
\hline & $\% /$ Mean \\
Yes & $(S D)$ \\
\hline Use of erectile dysfunction drugs & 14.6 \\
No & 69.5 \\
Yes & 30.5 \\
Group sex & \\
No & 80.5 \\
Yes & 19.5 \\
Condomless anal intercourse & \\
No & 48.8 \\
Yes & 51.2
\end{tabular}

Perceptions related to PrEP (among participants with $\quad(n=70)$ experience of SDU in the past year who were not on PrEP)

Willingness to take once-daily oral pill as PrEP in the next six months after being briefed some facts of PrEP
No (definitely not/probably not/neutral)
Yes (probably will/definitely will)
67.1

Willingness to pay (HK\$ per month) for using once-daily oral pill as PrEP (among those with willingness to take PrEP in the next six months, $n=$ 56)

$\begin{array}{ll}\leq 300 & 24.2 \\ 301-500 & 14.3 \\ 501-1000 & 18.6 \\ 1000-2000 & 21.4 \\ 2001-4000 & 17.1 \\ 4001-6000 & 2.9 \\ 6001-8000 & 1.4 \\ >8000 & 0.0\end{array}$

Perceptions related to PrEP based on the TPB

Positive attitudes toward PrEP (\% agree)

PrEP can reduce your chance of HIV infection during 81.4 SDU

PrEP would reduce your worry of HIV infection when 64.3 having condomless sex during SDU

PrEP provides you more choice for HIV prevention 84.3

Positive Attitude Scale ${ }^{a}$

Negative attitudes toward PrEP (\% agree)

Psychoactive substances that are used during SDU $\quad 17.1$ would reduce the protective effect of PrEP

Psychoactive substances that are used during SDU $\quad 30.0$ would aggravate the side-effects of PrEP

Psychoactive substances that are used during SDU 28.6 would make you forget to take PrEP

Daily use of PrEP would cause severe financial burden for you

You will be stigmatized by medical professionals when you are using PrEP-related services
1.4

4 4 .1 30.0 
Table 2 Patterns of SDU and perceptions related PrEP among GBMSM with experience of SDU in the past year (Continued)

\begin{tabular}{cc}
\hline & $\%$ / Mean \\
& (SD) \\
\hline Negative Attitude Scale & $10.2(2.2)$ \\
Perceived subjective norm related to PrEP & \\
People who are important to you will support you to use PrEP \\
Disagree/neutral & 32.9 \\
Agree & 67.1 \\
Perceived behavioral control to use PrEP & \\
In general, you are confident in taking PrEP every day in the next \\
six months
\end{tabular}

Sexualized drug use is defined as use of the following psychoactive substances before/during anal intercourse, including ketamine, methamphetamine, cocaine, cannabis, ecstasy, Dormicum/Halcion/Erimin 5/ non-prescription hypnotic drugs, heroin, cough suppressant (not for curing cough), amyl nitrite (popper), GHB/GBL ( $ү$-hydroxybutyrate), 5-methoxy- $\mathrm{N}, \mathrm{N}$ diisopropyltryptamine (Foxy), and mephedrone

aPositive Attitude Scale, three items, Cronbach's alpha: 0.648 , one factor was identified by explanatory factor analysis, explaining for $61.6 \%$ of the total variance. Higher score of the scale indicated more positive attitudes toward PrEP

${ }^{b}$ Negative Attitude Scale, five items, Cronbach's alpha: 0.747 , one factor was identified by explanatory factor analysis, explaining for $56.6 \%$ of the total variance. Higher score of the scale indicated more negative attitudes toward PrEP

supported by the results, as they had much higher PrEP uptake than those without such experience. Mathematical models suggested that achieving 75\% PrEP coverage among high-risk HIV-negative GBMSM in China would prevent $25.7 \%$ of new HIV infection among all GBMSM [62]. GBMSM with experience of recent SDU may be a priority group for future PrEP implementation. Strategies to increase PrEP access and coverage are hence needed for this group of GBMSM in Hong Kong.

Among GBMSM with experience of SDU in the past year who were not on PrEP, about $70 \%$ were willing to use daily PrEP in the next 6 months. The rate was higher than that of GBMSM in general in Hong Kong [27]. Data on willingness to pay suggested that the current market rate for obtaining PrEP in Hong Kong (HK\$8000 per month) was not affordable for this group of GBMSM, as none of them were willing to pay such amount. Future PrEP implementation in Hong Kong should take potential users' willingness to pay into consideration. Without affordable PrEP in Hong Kong, this group of GBMSM may seek cheaper PrEP from informal channels (e.g., online purchases or oversea clinics) [3]. Previous studies showed that informal GBMSM PrEP users often reported suboptimal adherence, risk compensation, and not taking up required testing [63]. These issues threaten their safety.
To achieve high coverage of PrEP, health promotion is needed even after affordable PrEP is available in Hong Kong. Findings of this study provided some insights for promoting PrEP among Hong Kong GBMSM with experience of recent SDU. Those who had taken up HIV testing in the past year showed higher willingness to use PrEP. HIV testing and counseling may be an ideal setting to promote PrEP, as confirmed HIV-negative serostatus is a prerequisite for initiate PrEP, and users may already be motivated to take up HIV protective measures and should be more ready to use PrEP [64]. Local NGO may play an important role in future PrEP implementation, as they are main providers of HIV testing services for GBMSM in Hong Kong [65].

Our results also suggested that increasing positive attitudes toward PrEP, creating subjective norm supporting PrEP use, and enhancing perceived behavioral control of using PrEP are potential useful strategies to promote PrEP, as these factors were significantly associated with willingness to use PrEP. Health communication messages should emphasize PrEP is an effective strategy in preventing HIV during SDU. Future health promotion should also encourage GBMSM with experience of SDU to discuss PrEP with their significant others to obtain support. Simplification of the procedures to obtain PrEP and provision of gay-friendly services may be useful strategies to enhance perceived behavioral control of using PrEP. In contrast to our hypothesis, negative attitudes such as concerns about psychoactive substances would reduce effectiveness, increase severity of side effects or risk of non-adherence, or lead to stigmatization originated from service providers were not significantly associated with willingness to use PrEP. Removing these negative attitudes may not be useful strategies to promote PrEP in this group.

In addition, our study also showed that prevalence of SDU and chemsex among GBMSM in Hong Kong was lower than that of Western Europe, Australia, the United States and mainland China [5, 6, 10-14]. Similar to previous findings, SDU in the past year was associated with higher prevalence of anal intercourse with NRP and CAI with men. Among GBMSM with experience of SDU in the past year, many of them engaged in SDU frequently, and reported CAI and group sex during SDU. Since we did not assess adoption of biobehavioral or behavioral risk reduction strategies (e.g., negotiated safety, serosorting, etc.) during sexual encounters, CAI might not represent high risk of HIV/STI infection. Future studies investigating sexual behaviors during SDU should take adoption of these biobehavioral or behavioral risk reduction strategies into account.

This study was one of the first studies looking at PrEP use among Chinese GBMSM with experience of recent SDU. However, it had some limitations. First, the small 
Table 3 Associations between background characteristics and willingness to take once-daily oral pill as PrEP in the next six months (among GBMSM with experience of SDU in the past year who were not on PrEP, $n=70$ )

\begin{tabular}{|c|c|c|}
\hline & Row\% & OR $(95 \% \mathrm{Cl})$ \\
\hline \multicolumn{3}{|l|}{ Socio-demographic characteristics } \\
\hline \multicolumn{3}{|l|}{ Age group } \\
\hline $18-30$ & 53.2 & 1.0 \\
\hline $31-40$ & 57.8 & $0.55(0.19,1.59)$ \\
\hline$>40$ & 77.8 & $1.40(0.25,7.93)$ \\
\hline \multicolumn{3}{|l|}{ Highest educational level attained } \\
\hline Senior high or below & 83.3 & 1.0 \\
\hline College or above & 61.5 & $0.32(0.08,1.25) \dagger$ \\
\hline \multicolumn{3}{|l|}{ Current marital status } \\
\hline Currently single & 69.0 & 1.0 \\
\hline Married/cohabited with a man & 64.3 & $0.81(0.29,2.22)$ \\
\hline \multicolumn{3}{|l|}{ Monthly personal income (HK\$) } \\
\hline$<10,000$ & 75.0 & 1.0 \\
\hline $10,000-19,999$ & 74.1 & $0.95(0.20,4.55)$ \\
\hline $20,000-39,999$ & 63.6 & $0.58(0.12,2.80)$ \\
\hline 40,000 and above & 44.4 & $0.27(0.04,1.70)$ \\
\hline \multicolumn{3}{|l|}{ Current employment status } \\
\hline Full-time & 67.9 & 1.0 \\
\hline $\begin{array}{l}\text { Part-time/unemployed/retired/ } \\
\text { students }\end{array}$ & 64.7 & $0.87(0.27,2.73)$ \\
\hline \multicolumn{3}{|l|}{ Sexual orientation } \\
\hline Homosexual & 66.2 & 1.0 \\
\hline Bisexual & 80.0 & $2.05(0.22,19.43)$ \\
\hline \multicolumn{3}{|l|}{ Channels of recruitment } \\
\hline Outreach in gay venues & 73.3 & 1.0 \\
\hline Online recruitment & 68.4 & $0.79(0.21,2.99)$ \\
\hline Peer referral & 58.8 & $0.52(0.12,2.32)$ \\
\hline
\end{tabular}

\section{Service utilization}

HIV testing in the last 12 months

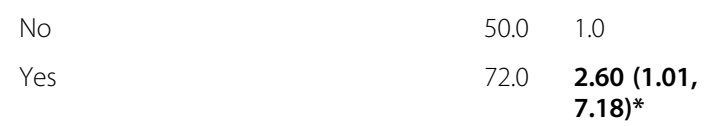

Other HIV prevention services in the last 12 months (e.g., condom distribution, peer education, pamphlet and lectures)

$\begin{array}{lll}\text { No } & 73.9 & 1.0 \\ \text { Yes } & 63.8 & 0.62(0.21,1.88)\end{array}$

Drug cessation/rehabilitation services provided by governmental organizations

$\begin{array}{lll}\text { No } & 69.1 & 1.0 \\ \text { Yes } & 0.0 & \text { N.A. }\end{array}$

Drug cessation/rehabilitation services provided by non-governmental organizations

No

$68.3 \quad 1.0$
Table 3 Associations between background characteristics and willingness to take once-daily oral pill as PrEP in the next six months (among GBMSM with experience of SDU in the past year who were not on PrEP, $n=70$ ) (Continued)

\begin{tabular}{lll}
\hline \multicolumn{4}{c}{ Row\% } & OR $(95 \% \mathrm{Cl})$ \\
\hline Yes & 57.1 & $0.62(0.13,3.04)$ \\
History of sexual transmitted infections/viral hepatitis \\
History of other sexually transmitted infections \\
No & 68.0 & 1.0 \\
Yes & 65.0 & $0.87(0.29,2.61)$
\end{tabular}

\section{Sexual behaviors in the last 12 months}

Had had anal intercourse with regular male sex partners (RP)

$$
\begin{array}{lll}
\text { No } & 68.8 & 1.0 \\
\text { Yes } & 66.7 & 0.91(0.27,3.02)
\end{array}
$$

Had had anal intercourse with non-regular male sex partners (NRP)

$\begin{array}{lll}\text { No } & 57.1 & 1.0 \\ \text { Yes } & 68.3 & 1.61(0.33,7.89)\end{array}$

OR: crude odds ratios

OR and 95\% were bold for variables with $p<0.05$

$+0.05<P<0.10, * P<0.05$

N.A. Not applicable

sample size of GBMSM with experience of SDU in the past year was one major limitation of this study. Only 70 GBMSM with such experience were asked about willingness to use PrEP and perceptions related to PrEP. This was a pilot study providing some preliminary data among this group of GBMSM with particularly high risk of HIV infection. Second, we did not ask PrEP-related questions among participants without experience of recent SDU. We were not able to compare perceptions related PrEP between GBMSM with and without experience of recent SDU. Third, we did not ask whether participants used PrEP or adopted other behavioral strategies (e.g., negotiated safety) during sexual encounters. Without measuring adoption of biobehavioral or behavioral risk reduction strategies, CAI might not represent high risk of HIV/STI infection. Fourth, participants were recruited by non-probabilistic sampling in the absence of sampling frame. As compared to a representative GBMSM survey in Hong Kong [3], our participants reported lower level of CAI, but higher HIV testing rate. Fifth, we were not able to obtain characteristics of participants who refused to join the study; selection bias might exist. Moreover, the results were self-reported and were collected via telephone interview, social desirability bias might exist. The prevalence of SDU, chemsex, CAI with men and multiple male sex partnerships may be under-reported. Furthermore, we did not ask participants' willingness to use on-demand PrEP [66]. The willingness to use PrEP may be underestimated. Finally yet importantly, this was a cross-sectional survey and could not establish causal relationship. 
Table 4 Factors associated with willingness to take once-daily oral pill as PrEP in the next six months (among GBMSM with experience of SDU in the past year and were not on PrEP, $n=70$ )

\begin{tabular}{|c|c|c|}
\hline & OR $(95 \% \mathrm{Cl})$ & AOR $(95 \% \mathrm{Cl})$ \\
\hline \multicolumn{3}{|l|}{ Patterns of SDU } \\
\hline \multicolumn{3}{|c|}{ Poly-use of psychoactive substances during SDU the past year } \\
\hline No & 1.0 & \\
\hline Yes & $2.02(0.58,7.01)$ & - \\
\hline \multicolumn{3}{|l|}{ Time since the first episode of SDU } \\
\hline$<1$ year & 1.0 & \\
\hline $1-2$ years & $1.00(0.21,4.77)$ & \\
\hline $3-5$ years & $1.14(0.25,5.33)$ & \\
\hline$>5$ years & $0.59(0.18,1.96)$ & - \\
\hline \multicolumn{3}{|l|}{ Frequency of SDU in the past year } \\
\hline 1 episode/month & 1.0 & \\
\hline 1-2 episodes/month & $0.81(0.25,2.67)$ & \\
\hline$\geq 3$ episodes/month & $1.33(0.39,4.58)$ & - \\
\hline \multicolumn{3}{|l|}{ Condomless anal intercourse in the past year } \\
\hline No & 1.0 & \\
\hline Yes & $0.88(0.32,2.40)$ & - \\
\hline \multicolumn{3}{|l|}{ Perceptions related to PrEP } \\
\hline Positive Attitude Scale & $2.30(1.46,3.62)^{* * *}$ & $2.37(1.47,3.82)^{* * *}$ \\
\hline Negative Attitude Scale & $1.16(0.91,1.47)$ & - \\
\hline \multicolumn{3}{|c|}{ People who are important to you will support you to use PrEP } \\
\hline Disagree/neutral & 1.0 & 1.0 \\
\hline Agree & $9.14(2.90,28.77)^{* * *}$ & $9.67(2.95,31.71)^{* * *}$ \\
\hline \multicolumn{3}{|c|}{ In general, you are confident in taking PrEP every day in the next six months } \\
\hline Strongly disagree/disagree/neutral & 1.0 & 1.0 \\
\hline Agree/strongly agree & $20.57(5.75,73.65)^{* * *}$ & $19.68(5.44,71.26)^{* * *}$ \\
\hline \multicolumn{3}{|l|}{ Mental health status } \\
\hline \multicolumn{3}{|l|}{ Depressive symptoms } \\
\hline No clinical depressive symptoms & 1.0 & \\
\hline Presence of clinical depressive symptoms & $0.88(0.32,2.40)$ & - \\
\hline \multicolumn{3}{|l|}{ Anxiety } \\
\hline No/mild/anxiety & 1.0 & \\
\hline Severe anxiety & $0.46(0.08,2.45)$ & - \\
\hline
\end{tabular}

\section{OR: crude odds ratios}

AOR: multivariate odds ratios obtained by multivariate logistic regression using variables in Tables 3 and 4 that were found to be statistically significant in the univariate analysis as candidates

95\% Cl 95\% confidence interval

OR, AOR and $95 \%$ were bold for variables with $p<0.05$

*** $P<0.001,---$ : not considered in the model

\section{Conclusion}

GBMSM with experience of recent SDU are potentially good candidates of PrEP implementation. This group of GBMSM reported higher prevalence of PrEP uptake and willingness to use PrEP. Perceptions related to PrEP based on the TPB were significantly associated with willingness to use PrEP.

\section{Abbreviation}

GBMSM: Gay, bisexual and other men who have sex with men; HIV: Human Immunodeficiency virus; SDU: Sexualized drug use; CAl: Condomless anal intercourse; PrEP: Pre-exposure prophylaxis; NGO: Non-governmental organization; STI: Sexually transmitted infection; ORu: Univariate odds ratios; AOR: Adjusted odds ratios; Cl: Confidence interval; SD: Standard deviation

\section{Acknowledgements}

Not applicable. 


\section{Authors' contributions}

Author ZW and JTFL designed the study and wrote the protocol. Author ZW, $\mathrm{PM}$ and $\mathrm{Ml}$ designed the questionnaire and analytical plan. Author ZW and Ml supervised the data collection process. Author ZW, FY and Ml analyzed and interpreted the data and wrote the manuscript. Author ZW and JTFL revised the manuscript critically and finalized the paper. All authors contributed to and approved the final manuscript.

\section{Funding}

This study was supported by the Beat Drugs Fund, Narcotics Division Security Bureau of Hong Kong SAR, China (Ref\# 160051). The funder had no role in study design, collection, analysis or interpretation of the data, writing the manuscript, or the decision to submit the paper for publication.

\section{Availability of data and materials}

All data generated or analyzed during this study are included in this published article.

\section{Ethics approval and consent to participate}

All procedures performed in studies involving human participants were in accordance with the ethical standards of the Survey and Behavioral Research Ethics Committee of the Chinese University of Hong Kong and with the 1964 Helsinki declaration and its later amendments or comparable ethical standards. The ethics committee approved obtaining verbal instead of written informed consent. Fieldworkers signed a form pledging that the participants had been fully informed about the study.

\section{Consent for publication}

Not applicable.

\section{Competing interests}

The authors declare that they have no conflict of interest.

\section{Author details}

'Centre for Health Behaviours Research, JC School of Public Health and Primary Care, Faculty of Medicine, The Chinese University of Hong Kong, Hong Kong SAR, China. ${ }^{2}$ Shenzhen Research Institute, The Chinese University of Hong Kong, Shenzhen, China. ${ }^{3}$ Department of Early Childhood Education, Faculty of Education and Human Development, The Education University of Hong Kong, Hong Kong SAR, China.

\section{Received: 21 January 2020 Accepted: 12 April 2020}

Published online: 22 April 2020

\section{References}

1. Qin $Q$, Tang W, Ge L, Li D, Mahapatra T, Wang L, et al. Changing trend of HIV, Syphilis and Hepatitis C among Men Who Have Sex with Men in China. Sci Rep. 2016;6:31081.

2. Zhang W, Xu JJ, Zou H, Zhang J, Wang N, Shang H. HIV incidence and associated risk factors in men who have sex with men in mainland China: an updated systematic review and meta-analysis. Sex Health. 2016;13(4): 373-82.

3. Centre for Health Protection. Factsheet: PRiSM --- HIV prevalence and risk behavioural survey of men who have sex with men in Hong Kong 2017. 2018. Available at: https:/www.aids.gov.hk/english/surveillance/sur_report/ prism2017e.pdf.

4. Hong Kong Advisory Council on AIDS. Recommended HIV/AIDS strategies for Hong Kong (2017-2021). 2017. Available at: http://www.aca.gov.hk/ english/strategies/pdf/strategies17-21.pdf .

5. Evers YJ, Van Liere G, Hoebe C, Dukers-Muijrers N. Chemsex among men who have sex with men living outside major cities and associations with sexually transmitted infections: a cross-sectional study in the Netherlands. PLoS One. 2019;14(5):e0216732.

6. Hibbert MP, Brett CE, Porcellato LA, Hope VD. Psychosocial and sexual characteristics associated with sexualised drug use and chemsex among men who have sex with men (MSM) in the UK. Sex Transm Infect. 2019; 95(5):342-50.

7. Maxwell S, Shahmanesh M, Gafos M. Chemsex behaviours among men who have sex with men: a systematic review of the literature. Int I Drug Policy. 2019;63:74-89.
8. Edmundson C, Heinsbroek E, Glass R, Hope V, Mohammed H, White M, et al. Sexualised drug use in the United Kingdom (UK): a review of the literature. Int J Drug Policy. 2018;55:131-48.

9. Public Health England. Substance misuse services for men who have sex with men involved in chemsex. 2015. Available at: https:/assets.publishing. service.gov.uk/government/uploads/system/uploads/attachment_data/ file/669676/Substance_misuse_services_for_men_who_have_sex_with_ men_involved_in_chemsex.pdf.

10. Druckler S, van Rooijen MS, de Vries HJC. Chemsex among men who have sex with men: a sexualized drug use survey among clients of the sexually transmitted infection outpatient clinic and users of a gay dating app in Amsterdam, the Netherlands. Sex Transm Dis. 2018;45(5):325-31.

11. Park SH, Al-Ajlouni Y, Palamar JJ, Goedel WC, Estreet A, Elbel B, et al. Financial hardship and drug use among men who have sex with men. Subst Abuse Treat Prev Policy. 2018;13(1):19.

12. Ryan KE, Wilkinson AL, Pedrana A, Quinn B, Dietze P, Hellard M, et al. Implications of survey labels and categorisations for understanding drug use in the context of sex among gay and bisexual men in Melbourne, Australia. Int J Drug Policy. 2018:55:183-6.

13. Sewell J, Cambiano V, Speakman A, Lampe FC, Phillips A, Stuart D, et al. Changes in chemsex and sexual behaviour over time, among a cohort of MSM in London and Brighton: findings from the AURAH2 study. Int J Drug Policy. 2019;68:54-61.

14. Lim SH, Akbar M, Wickersham JA, Kamarulzaman A, Altice FL. The management of methamphetamine use in sexual settings among men who have sex with men in Malaysia. Int J Drug Policy. 2018;55:256-62.

15. Kohli M, Hickson F, Free C, Reid D, Weatherburn P. Cross-sectional analysis of chemsex drug use and gonorrhoea diagnosis among men who have sex with men in the UK. Sex Health. 2019;16(5):464-72.

16. Wong NS, Kwan TH, Lee KCK, Lau JYC, Lee SS. Delineation of chemsex patterns of men who have sex with men in association with their sexual networks and linkage to HIV prevention. Int J Drug Policy. 2019;75:102591.

17. Kurtz SP. Post-circuit blues: motivations and consequences of crystal meth use among gay men in Miami. AIDS Behav. 2005;9(1):63-72.

18. Coffin PO, Santos GM, Colfax G, Das M, Matheson T, DeMicco E, et al. Adapted personalized cognitive counseling for episodic substance-using men who have sex with men: a randomized controlled trial. AIDS Behav. 2014;18(7):1390-400.

19. Santos GM, Coffin PO, Vittinghoff E, DeMicco E, Das M, Matheson T, et al. Substance use and drinking outcomes in personalized cognitive counseling randomized trial for episodic substance-using men who have sex with men. Drug Alcohol Depend. 2014;138:234-9.

20. Kurtz SP, Stall RD, Buttram ME, Surratt HL, Chen M. A randomized trial of a behavioral intervention for high risk substance-using MSM. AIDS Behav. 2013;17(9):2914-26.

21. Mansergh G, Koblin BA, McKirnan DJ, Hudson SM, Flores SA, Wiegand RE, et al. An intervention to reduce HIV risk behavior of substance-using men who have sex with men: a two-group randomized trial with a nonrandomized third group. PLoS Med. 2010;7(8):e1000329.

22. Grant RM, Lama JR, Anderson PL, McMahan V, Liu AY, Vargas L, et al. Preexposure chemoprophylaxis for HIV prevention in men who have sex with men. N Engl J Med. 2010;363(27):2587-99.

23. Choopanya K, Martin M, Suntharasamai P, Sangkum U, Mock PA, Leethochawalit M, et al. Antiretroviral prophylaxis for HIV infection in injecting drug users in Bangkok, Thailand (the Bangkok Tenofovir study): a randomised, double-blind, placebo-controlled phase 3 trial. Lancet. 2013; 381(9883):2083-90.

24. World Health Organization. WHO expands recommendation on oral preexposure prophylaxis for HIV infection (PrEP). 2015. Available at: https:// www.who.int/hiv/pub/prep/policy-brief-prep-2015/en/.

25. Maxwell S, Gafos M, Shahmanesh M. Pre-exposure prophylaxis use and medication adherence among men who have sex with men: a systematic review of the literature. J Assoc Nurses AIDS Care. 2019;30(4):e38-61.

26. Peng P, Su S, Fairley CK, Chu M, Jiang S, Zhuang X, et al. A global estimate of the acceptability of pre-exposure prophylaxis for HIV among men who have sex with men: a systematic review and meta-analysis. AIDS Behav. 2018;22(4):1063-74.

27. Wang Z, Lau JTF, Fang Y, Ip M, Gross DL. Prevalence of actual uptake and willingness to use pre-exposure prophylaxis to prevent HIV acquisition among men who have sex with men in Hong Kong, China. PLoS One. 2018; 13(2):e0191671. 
28. Kwan TZ, Lee SS. Bridging awareness and acceptance of pre-exposure prophylaxis among men who have sex with men --- the need for targeting chem-sex and HIV testing: cross-sectional survey. JMIR Public Health Surveill. 2019;5(3):e13083.

29. Holloway IW, Dougherty R, Gildner J, Beougher SC, Pulsipher C, Montoya JA, et al. Brief report: PrEP uptake, adherence, and discontinuation among California YMSM using Geosocial networking applications. J Acquir Immune Defic Syndr. 2017;74(1):15-20.

30. Shrestha R, Altice FL, Huedo-Medina TB, Karki P, Copenhaver M. Willingness to use pre-exposure prophylaxis (PrEP): an empirical test of the informationmotivation-behavioral skills (IMB) model among high-risk drug users in treatment. AIDS Behav. 2017;21(5):1299-308.

31. Stein $M$, Thurmond $P$, Bailey $G$. Willingness to use HIV pre-exposure prophylaxis among opiate users. AIDS Behav. 2014;18(9):1694-700.

32. Kuo I, Olsen H, Patrick R, Phillips G 2nd, Magnus M, Opoku J, et al, Willingness to use HIV pre-exposure prophylaxis among communityrecruited, older people who inject drugs in Washington, DC. Drug Alcohol Depend. 2016;164:8-13.

33. Storholm ED, Volk JE, Marcus JL, Silverberg MJ, Satre DD. Risk perception, sexual behaviors, and PrEP adherence among substance-using men who have sex with men: a qualitative study. Prev Sci. 2017;18(6):737-47.

34. Michie S, Johnston M, Francis J, Hardeman W, Eccle M. From theory to intervention: mapping theoretically derived behaviorual determinants to behaviour change techniques. Appl Psychol. 2008;57:660-80.

35. Ajzen I. The theory of planned Behaivor. Organ Behav Human Decis. 1991; 50(2):179-211

36. Wang Z, Lau JTF, Yang X, Cai Y, Gross DL, Ma T, et al. Acceptability of daily use of Free Oral pre-exposure prophylaxis (PrEP) among transgender women sex Workers in Shenyang, China. AIDS Behav. 2017;21(12):3287-98.

37. Roth A, Felsher M, Tran N, Bellamy S, Martinez-Donate A, Krakower D, et al. Drawing from the theory of planned behaviour to examine pre-exposure prophylaxis uptake intentions among heterosexuals in high HIV prevalence neighbourhoods in Philadelphia, Pennsylvania, USA: an observational study. Sex Health. 2019;16(3):218-24.

38. Tseng YH, Cheng CP, Kuo SH, Hou WL, Chan TF, Chou FH. Safe sexual behaviors intention among female youth: the construction on extended theory of planned behavior. J Adv Nurs. 2020;76(3):814-23.

39. Chowdhuri RN, Pinchoff J, Boyer CB, Ngo TD. Exploring gender and partner communication: theory of planned behavior predictors for condom use among urban youth in Zambia. Int J Gynaecol Obstet. 2019;147(2):258-67.

40. Wu AMS, Lau JTF, Wang Z, Ma L. Prevalence and factors of concurrent multiple male sex partnership among men who have sex with men with regular sex Partners in Beijing, China. J Sex Marital Ther. 2019;45(3):247-58.

41. Niu L, Wang Z, Fang Y, Ip M, Lau JTF. Behavior intention to use routine optout HIV testing in primary care settings among men who have sex with men in China. AIDS Care. 2019;31(12):1565-73.

42. Yang $X$, Wang $Z$, Wang $X, M a T, X u e ~ H, H e ~ Y$, et al. Behavioral intention to initiate antiretroviral therapy (ART) among Chinese HIV-infected men who have sex with men having high CD4 count in the era of "treatment for all". Am J Mens Health. 2019;13(1):1557988319828615.

43. Batchelder AW, Safren S, Mitchell AD, Ivardic I, O'Cleirigh C. Mental health in 2020 for men who have sex with men in the United States. Sex Health. 2017;14(1):59-71.

44. King M, Semlyen J, Tai SS, Killaspy H, Osborn D, Popelyuk D, et al. A systematic review of mental disorder, suicide, and deliberate self harm in lesbian, gay and bisexual people. BMC Psychiatry. 2008:8:70.

45. Chi X, Hawk ST. Attitudes toward Same-Sex Attraction and Behavior among Chinese University Students: Tendencies, Correlates, and Gender Differences. Front Psychol. 2016;7:1592.

46. Yu L, Jiang C, Na J, Li N, Diao W, Gu Y, et al. Elevated 12-month and lifetime prevalence and comorbidity rates of mood, anxiety, and alcohol use disorders in Chinese men who have sex with men. PLoS One. 2013:8(4): e50762

47. Liu J, Yi Z, Zhao Y, Qu B, Zhu Y. The psychological health and associated factors of men who have sex with men in China: a cross-sectional survey. PLoS One. 2018;13(5):e0197481.

48. Carrico AW, Pollack LM, Stall RD, Shade SB, Neilands TB, Rice TM, et al. Psychological processes and stimulant use among men who have sex with men. Drug Alcohol Depend. 2012;123(1-3):79-83.

49. Hegazi A, Lee MJ, Whittaker W, Green S, Simms R, Cutts R, et al. Chemsex and the city: sexualised substance use in gay bisexual and other men who have sex with men attending sexual health clinics. Int J STD AIDS. 2017; 28(4):362-6.

50. Kecojevic A, Wong CF, Corliss HL, Lankenau SE. Risk factors for high levels of prescription drug misuse and illicit drug use among substance-using young men who have sex with men (YMSM). Drug Alcohol Depend. 2015;150:15663.

51. Pufall EL, Kall M, Shahmanesh M, Nardone A, Gilson R, Delpech V, et al. Sexualized drug use ('chemsex') and high-risk sexual behaviours in HIVpositive men who have sex with men. HIV medicine. 2018;19(4):261-70.

52. Velloza J, Baeten JM, Haberer J, Ngure K, Irungu E, Mugo NR, et al. Effect of depression on adherence to Oral PrEP among men and women in East Africa. J Acquir Immune Defic Syndr. 2018;79(3):330-8.

53. Ogunbajo A, Kang A, Shangani S, Wade RM, Onyango DP, Odero WW, et al. Awareness and acceptability of pre-exposure prophylaxis (PrEP) among gay, bisexual and other men who have sex with men (GBMSM) in Kenya. AIDS Care. 2019;31(10):1185-92.

54. Wang Z, Lau JTF, Ip M, Ho SPY, Mo PKH, Latkin C, et al. A randomized controlled trial evaluating efficacy of promoting a home-based HIV selftesting with online counseling on increasing HIV testing among men who have sex with men. AIDS Behav. 2018;22(1):190-201.

55. Boey KW. Cross-validation of a short form of the CES-D in Chinese elderly. Int J Geriatr Psychiatry. 1999;14(8):608-17.

56. Li D, Li C, Wang Z, Lau JT. Prevalence and associated factors of unprotected anal intercourse with regular male sex partners among HIV negative men who have sex with men in China: a cross-sectional survey. PLoS One. 2015; 10(3):e0119977.

57. Su X, Zhou AN, Li J, Shi LE, Huan X, Yan H, et al. Depression, loneliness, and sexual risk-taking among HIV-negative/unknown men who have sex with men in China. Arch Sex Behav. 2018;47(7):1959-68.

58. Spitzer RL, Kroenke K, Williams JB, Lowe B. A brief measure for assessing generalized anxiety disorder: the GAD-7. Arch Intern Med. 2006;166(10): 1092-7.

59. Parsons JT, Rendina HJ, Lassiter JM, Whitfield TH, Starks TJ, Grov C. Uptake of HIV pre-exposure prophylaxis (PrEP) in a National Cohort of gay and bisexual men in the United States. J Acquir Immune Defic Syndr. 2017;74(3): 285-92.

60. Ko NY, Chen BJ, Li CW, Ku WW, Hsu ST. Willingness to self-pay for preexposure prophylaxis in men who have sex with men: a National Online Survey in Taiwan. AIDS Educ Prev. 2016;28(2):128-37.

61. Zhang $Y$, Peng B, She $Y$, Liang $H$, Peng HB, Qian HZ, et al. Attitudes toward HIV pre-exposure prophylaxis among men who have sex with men in western China. AIDS Patient Care STDs. 2013;27(3):137-41.

62. Li J, Peng L, Gilmour S, Gu J, Ruan Y, Zou H, et al. A mathematical model of biomedical interventions for HIV prevention among men who have sex with men in China. BMC Infect Dis. 2018;18(1):600.

63. Rivierez I, Quatremere G, Spire B, Ghosn J, Rojas CD. Lessons learned from the experiences of informal PrEP users in France: results from the ANRSPrEPage study. AIDS Care. 2018;30(sup2):48-53.

64. Lau JT, Wang Z, Kim JH, Lau M, Lai CH, Mo PK. Acceptability of HPV vaccines and associations with perceptions related to HPV and HPV vaccines among men who have sex with men in Hong Kong. PLoS One. 2013:8(2):e57204.

65. Wong HT, Tam HY, Chan DP, Lee SS. Usage and acceptability of HIV selftesting in men who have sex with men in Hong Kong. AIDS Behav. 2015: 19(3):505-15.

66. Hall EW, Heneine W, Sanchez T, Sineath RC, Sullivan P. Preexposure prophylaxis modality preferences among men who have sex with men and use social media in the United States. J Med Internet Res. 2016;18(5):e111.

\section{Publisher's Note}

Springer Nature remains neutral with regard to jurisdictional claims in published maps and institutional affiliations. 